\title{
La enseñanza de las primeras letras a las niñas de Puebla. Un estudio a partir de sus reglamentos: 1790-1843
}

\author{
Early Literacy Instruction for Girls \\ in the City of Puebla. A Study \\ through Regulations: 1790-1843
}

\author{
Rosario Torres Dominguez \\ Facultad de Filosofía y Letras, \\ Universidad Autónoma de Puebla \\ torresro46@gmail.com
}

\section{Resumen}

\begin{abstract}
En Puebla, el proceso de incorporación de las mujeres a la enseñanza de las primeras letras fue lento y de larga duración. Las características de las nuevas instituciones que se crearon para trasmitir esas enseñanzas fueron muy parecidas a las escuelas coloniales. Escuelas conventuales, escuelas de la Junta de Caridad y escuelas municipales siguieron el mismo método y materias de enseñanza. Si bien ampliaron la enseñanza de la lectura y escritura a las niñas de todas las clases sociales, la falta de recursos limitó el número de escuelas. En 1842, apenas había dos escuelas gratuitas. Pese a los reclamos de los hombres ilustrados, la educación de las niñas, terminaba a los 11 años y era la adecuada para administrar un hogar, destino inevitable de las mujeres en el periodo.
\end{abstract}

Palabras clave: Primeras letras, educación, ilustración, conocimientos útiles.

\begin{abstract}
In Puebla, the process of incorporating women into early literacy teaching was long and slow. The characteristics of the new institutions created to provide training in this area were very similar to the schools of the colonial period. Convent schools, Junta de Caridad (Charity Board) schools and municipal schools all used the same teaching methods and materials. Although they extended the teaching of reading and writing skills to include girls from all social classes, a lack of resources limited the number of schools. In 1842, a mere two free schools existed. Despite the complaints of more
\end{abstract}


enlightened men, education for girls concluded at the age of eleven and equipped them for nothing more than managing a household, the unquestioned fate of all women of the period.

Key Words: First letters, enlightenment, education, useful knowledge.

\section{Introducción}

En la segunda mitad el siglo XVIII, parecía que los patrones tradicionales de educación de las mujeres en la Nueva España cambiarían. Los hombres de la llustración habían declarado que era necesario abandonar la tradición e instruir mejor a las niñas. Decían que las mujeres, igual que los hombres, debían recibir educación; ambos podían contribuir en la riqueza moral y económica del reino. Carlos III prestó atención especial a la enseñanza, y dictó normas para la apertura de escuelas gratuitas de niñas. Se buscaba que en ellas, las niñas aprendieran a leer, escribir y contar, que se les habilitara con conocimientos útiles como la costura, el bordado o el dibujo. Además, que se formaran en principios religiosos, morales y civiles que les permitieran incorporarse a la sociedad.

Después de la Independencia, en México todas las opiniones estaban convencidas de la necesidad de educación a las mujeres y del enorme abandono en que ésta se encontraba. Sectores pensantes de la sociedad criticaban la diferencia de educación entre hombres y mujeres. Las niñas apenas recibían instrucción, y cuando lo hacían (reclamaban), ésta se limitaba a reforzar los saberes domésticos. Con el establecimiento de la República, algunas voces pensaron encontrar en las mujeres apoyo para la consolidación de este sistema de gobierno. Pero para volver realidad este deseo era necesario que las mujeres aprendieran a leer, escribir y contar. Como madres y esposas, las mujeres son las encargadas de educar y formar a los hijos, conociendo las nuevas ideas podrían trasmitirlas desde la tierna edad a sus hijos.

A finales del siglo XVIII, la ciudad de Puebla, como toda Nueva España, vivió el cambio en la educación de las niñas. ¿Cómo fue ese cambio?; ¿qué propuestas, se hicieron?; ¿qué finalidades tuvieron las escuelas de niñas?; ¿cómo operaban las escuelas?

Precisamente, el tema de este artículo es la enseñanza de las primeras letras a las niñas en Puebla. La idea es analizar cómo en la llamada Ciudad de los Ángeles se fueron creando los espacios de enseñanza para niñas. Nuestro propósito es hacer un seguimiento del proceso para comprobar la distancia que hubo entre el discurso y la realidad en la que quedó la enseñanza de las niñas. El estudio se centra en el periodo de transición de la Colonia a la primera mitad del siglo XIX. Los límites del trabajo son las fuentes documentales localizadas, principalmente: reglamentos de escuelas gratuitas.

Trabajos sobre educación de las mujeres en el periodo posterior a la Independencia, los encontramos en obras generales de Historia de la Educación. Uno de los primeros es el de 
Dorothy Tanck, publicado en 1977. La autora realiza un minucioso examen de la organización de la educación en la ciudad de México, desde finales de la Colonia hasta la primera República federal. Cuando describe las diferentes escuelas y la vida escolar de la capital, tiene oportunidad de ocuparse de la educación de las niñas. Nos dice, entonces, que quien se ocupaba de la enseñanza de las niñas eran las llamadas "amigas", escuelas heredadas del periodo colonial. Las maestras para adquirir una licencia debían primero cumplir ciertos requisitos, pero no se les exigía tener habilidad para enseñar a leer o escribir; sólo conocimientos de Doctrina Cristiana. Prácticamente estas escuelas, comenta la autora, eran como guarderías para niños pequeños (Tanck, 1977: 160).

Agrega que en las primeras décadas del siglo XIX, la sociedad capitalina empezó a preocuparse por la calidad de la educación de las niñas. Periódicos como el Diario de México (dirigido por Carlos María Bustamante y Wenceslao Barquera) empezaron a publicar artículos sobre los avances pedagógicos en Europa. También, por medio de la Gaceta de México los lectores se enteraban de los exámenes públicos de las escuelas españolas en las que las mismas alumnas reclamaban derecho a la educación, derecho que los hombres les han negado por considerarlas incapaces de recibirla (Tanck, 1977: 166).

Otras voces hablaron de la necesidad de mejorar la educación de las mujeres, en algo más que aprender a "coser, bordar y medio leer... sin considerar que las mujeres necesitan de otras luces", tanto para desempeñar su papel de madre de familia, como para manejarse en cualquier otra situación. Esas voces, propusieron cambiar de nombre a las escuelas de niñas en vez de "amigas" y ofrecer un curso completo de primeras letras, incluyendo aritmética e historia religiosa (Tanck, 1977: 166).

En el mismo tenor, menciona la autora otras críticas interesantes, como la de Tomás Salgado, que apuntaba a la profesión de maestras - profesión a la cual se llegaba por el sólo hecho de ser viejas y necesitadas-. León Ignacio Pico define la profesión de maestras como la de "ancianas ignorantísimas o fanáticas o visionarias, sin educación y sin principios, que emprenden esa carrera sólo porque no pueden mantenerse en otra...". Estos ejemplos dan una idea de las condiciones en que se encontraba la educación para las niñas y las voces de ilustrados que se levantaban para reclamar mayor atención.

Otro trabajo clave para conocer aspectos de la educación de las mujeres en el periodo mencionado, es el de Anne Staples, historiadora de la educación en México y pionera de este tipo de estudios. Su obra se ocupa del periodo que va entre los gobiernos de Iturbide a Juárez. La autora califica a la "amiga" como espacio doméstico para recibir niñas o niños pequeños, menores de cinco años, a cambio de una cuota. Con estudios muy limitados, las "amigas" eran la única experiencia académica abierta a las niñas (Staples, 2005: 382).

Nos dice que la enseñanza escolarizada de las mujeres hasta mediados del siglo XIX, no pasó de las primeras letras, otros conocimientos más especializados sólo se conseguían con 
maestros particulares. Voces dentro de la sociedad de la capital, comenzaron su reclamo para elevar el nivel de preparación. Condenaban el régimen monacal de educación y sus resultados. Sin embargo, la tendencia general fue ignorar la educación femenina, bajo el argumento de falta de dinero (Staples, 2005: 387). La educación de las mujeres, más que intelectual, las condicionaba a desempeñar el rol de género que les correspondía en la sociedad, y en donde las "ciencias del hogar" eran la esencia de la educación. Algunas mujeres pugnaban por estudios superiores, inaccesibles para ellas. Sin embargo, esa limitación no impedía que muchas tuvieran una vida activa en el comercio, el magisterio, o en la dirección de imprentas (Staples, 2005: 389). Hubo acuerdo en las opiniones de clérigos, políticos, literatos, abogados o educadores; todos coincidían en la necesidad de promover la educación femenina. Esto por tres razones: por el bien de los hijos, para ser buena compañera del marido y por ella misma. Comenta la autora, que en estas razones no aparece la idea expresada por Jovellanos, de que la mujer podría contribuir a crear riquezas para el Estado (Staples, 2005: 390).

Efectivamente, el sistema educativo no respaldó la participación de las mujeres en la construcción del nuevo Estado, y si pocas eran las ventajas de la educación para las mujeres de la ciudad, las del medio rural no tenían más opción que aprender lo básico que necesitaban para sobrevivir. En general, los efectos de la mala educación a las mujeres lo sufrían pobres y ricas (Staples, 2005: 392). Afirma la autora que la enseñanza de las primeras letras, en escuela pública, particular o en casa, fue más amplia para la mujer. A los niños se les enseñaba lo tradicional, a las niñas se les agregaban costura, bordado y otras habilidades domésticas. Sin embargo, la diferencia entre hombres y mujeres no radicaba en la enseñanza, sino en las oportunidades que se les negaban a las mujeres después de la escuela de primeras letras. Concluida esta instrucción, sólo quedaba el hogar, único ámbito que la sociedad aprobaba para la mujer (Staples, 2005: 396).

Sobre el mismo tema, hay dos pequeñas antologías de textos, preparadas, una por Pilar Gonzalbo para el periodo colonial y otra por Anne Staples para el México Independiente. Nos interesan los dos últimos textos de la primera antología: uno de Vicenta Vetancourt y otro de Ana Josefa Caballero de la Borda. El primero es un impreso de dos hojas en donde se anuncia una escuela de niñas. Inicia diciendo que la educación de las mujeres es un derecho natural, pero para que se cumpla es necesaria una "educación ilustre" (Vetancourt, 1985: 145). Las mujeres, igual que los hombres, tienen derecho a una educación moral, civil y científica, porque como madres deben educar a sus pequeños hijos, como viudas hacen el oficio de padres y como esposas viven entre los hombres y forman con ellos una sociedad doméstica. Los maridos necesitan que sus mujeres tengan una educación civil y moral, y una instrucción científica para vivir con ellas en forma racional. De no tener esta educación, no sabrán dirigir sus casas y familias, ni seguir en el trato y comercio humano un discurso o conversación discreta, dulce y agradable (Vetancourt, 1985: 145). Para lograr estos propósi- 
tos, ella propone en la enseñanza de las primeras letras las siguientes materias: ortografía, caligrafía, gramática castellana, ortología, aritmética, costura, bordado, hacer flores y demás habilidades "propias del sexo" [sic]. Al respecto, aclara la compiladora, que la simple mención de las materias contradecía el tono ilustrado de los objetivos enunciados al principio (Vetancourt, 1985: 146).

El siguiente texto es el discurso preliminar del Reglamento interior, que serviría de norma a los directores, maestra y niñas de la Academia Mexicana. La autora inicia diciendo que la educación de las mujeres es la más abandonada, una educación supersticiosa, rutinaria y mezquina; el resultado ha generado mujeres que no saben dirigir sus casas y familias, mujeres que sin educación se veían precisadas a educar a sus hijos física y moralmente, que no pueden presentar hombres instruidos ni útiles a la patria (Caballero, 1985: 149). Las mujeres de América, por la forma en que las educaron, carecen de virtudes morales y civiles, y abundan en caprichos extravagantes. Que con su adhesión al lujo han provocado la ruina de fortunas. Los hombres consideran a sus mujeres como muebles de lujo y no de utilidad, no tienen una compañera sino una estatua en que recrearse (Caballero, 1985: 150). Sin embargo, dice que esos defectos se quitan con una cristiana y culta educación, por eso clama por una reforma en la instrucción. Gonzalbo aclara que todo el discurso en contra de la educación tradicional de las niñas se viene abajo al leer las disposiciones del internado, todas muy parecidas a las del régimen anterior de las escuelas durante la época colonial (Caballero, 1985: 149).

En general, en estas obras vemos desfilar reclamos de las mentes ilustradas, por el abandono en que se hallaba la educación de las mujeres e ideas de cómo mejorarla. Pero, pese a todos los discursos, en la práctica la educación femenina siguió manteniendo a las mujeres dentro de los marcos del hogar, con una enseñanza religiosa, rutinaria y limitada.

\section{La educación colonial}

Sabemos que la educación de las niñas en el periodo colonial, estaba limitada al conocimiento de la Doctrina Cristiana, las labores de costura, cocina, flores artificiales y algunos elementos de lectura y escritura. Sin embargo, las opciones de estudio estaban determinadas por el estatus social; las niñas con recursos podían tener un maestro particular, que les enseñara - algunas veces - no sólo a leer y escribir, sino también que las iniciara en la música, algún idioma y otras habilidades. También podían ingresar al convento a recibir preparación mientras llegara la hora de casarse. Las niñas pobres, en cambio, tenían pocas opciones; para ellas únicamente estaban las "amigas" o los colegios gratuitos de parroquias o conventos. En estas instituciones pocas veces se aprendía a leer o escribir. 
En Puebla, desde la segunda mitad del siglo XVI, se instituyeron colegios para niñas, cada uno con diferentes propósitos. Entre ellos tenemos al Colegio de Jesús María, anexo al convento de San Gerónimo, fundado por el capitán Juan García Barranco para niñas vírgenes de familias nobles de la ciudad. Se buscaba que las niñas recibieran allí " [...] ejemplo de virtudes cristianas, conocimientos útiles para el perfecto y decoroso manejo de un hogar, así como principios literarios que se consideraran convenientes proporcionar a las mujeres". (Rodríguez, 2014: 77).

El fundador le otorgó al colegio la cantidad de 20 mil pesos y las casas para su morada. En 1702, la renta del colegio aumentó gracias a la donación de 38 mil pesos que hizo el deán de la Catedral, Don Diego Victoria de Salazar (Veytia, 1963: 511). Se dice que en tiempos del obispo Santa Cruz (1677-1699), el número de alumnas llegó a 22 colegialas (Leich, 1980: 205-206).

Otro colegio de niñas fue el de las Vírgenes de la Purísima Concepción, establecido por el obispo Juan de Palafox en el edificio del antiguo hospital de San Juan de Letrán. El mismo prelado nombró a un eclesiástico como rector, para que administrara sus rentas, las cuales ascendían a 90 mil 310 pesos (Veytia, 1963: 518). Para el gobierno interior se nombró a una rectora. Dicho colegio estaba destinado a niñas huérfanas y abandonadas, "[...] para que se criaran, con recogimiento y virtud, y después de las costumbres, les enseñen las labores y otras cosas, que es necesario aprendan y sepan las mujeres, para vencer la ociosidad, aún más contagiosa en ellas que en los hombres..." (De la Torre Villar, 1988: 87). Gracias a las donaciones de algunas cofradías y otros particulares, se podían dotar algunas huérfanas para que pudieran casarse o ingresaran a algún convento.

En 1677, el obispo Fernández de Santa Cruz emprendió la erección de cuatro colegios para mujeres, doncellas o casadas "descarriadas o separadas de sus maridos". Para las primeras, estableció el Colegio de Santa Gertrudis y para las doncellas el de San José. Con iguales propósitos, fundó otras dos instituciones, una en Tlaxcala, bajo la advocación de San José de Gracia y otra en Atlixco con el nombre de Santa Teresa. Durante el gobierno del obispo Pedro Nogales Dávila, como el dinero no alcanzaba para su manutención, se determinó cambiar las escuelas foráneas a la ciudad de Puebla y fusionar todas en dos, una para doncellas y otra para casadas/viudas, con el nombre de San José de Gracia y Santa Teresa (De la Torre Villar, 1988: 92).

Al parecer, con el paso del tiempo, las dos escuelas quedaron unidas en una. Porque en 1790, el obispo Benito Crespo les dio ordenanzas con el título de Constituciones y reglas que han de guardar y cumplir la rectora, vicerrectora y niñas colegialas del colegio de San José de Gracia y Santa Teresa de Jesús de la ciudad de la Puebla de los Ángeles. Hechas y ordenadas por el Ilustrísimo Señor Dr. Don Benito Crespo del Orden de Santiago, Obispo de dicha ciudad y 
obispado del Consejo de S.M. Trasladas fielmente de su original por orden de Doña Josefa de San Gregorio, actual rectora de dicho colegio, a 24 de septiembre del año de 1790.1

Dispuso el obispo para el gobierno interior del colegio, una rectora y una vicerrectora. La primera sería nombrada por el mismo prelado de la diócesis. En su poder quedaban las llaves del colegio, "del comulgatorio, confesionario, reja y portería", ella decidía qué persona podía entrar al colegio y quién no convenía. La segunda, nombrada en iguales condiciones que la rectora, debía asistir al lado de las colegialas a la sala de labor y permanecer con ellas todo el tiempo necesario. Para cuando alguna alumna deseara ausentarse pudiera darle o no autorización.

Las niñas aspirantes a ingresar al colegio, debían ser "limpias de sangre", españolas, doncellas y de dos años de edad, quedaba estrictamente prohibido el ingreso de mujeres mayores de edad. No estaba permitido que las alumnas llegaran a la portería, sólo los días de visita, que eran cada 15 días. Debían levantarse, desde la Pascua de resurrección hasta San Miguel, a las cinco de la mañana, y desde San Miguel a la Pascua a las 6 a. m.

Luego de levantarse, debían asistir al coro, para tener media hora de oración, y después de oír misa, reunidas, tomar el desayuno. A las 9 a. m., debían asistir a la sala de labor, donde la lectora de la comunidad "[...] tomará un libro espiritual o vida de un santo y lo leerá hasta las once". ${ }^{2}$ A las 11:30 debían pasar al refectorio a comer. En este lugar, mientras la lectora leía un libro devoto, dos niñas servían la mesa con "devoción y humildad".

Al acabar de comer, todas de pie, rezaban tres Padres Nuestros, después acudían al coro a rezar otros tres Padres Nuestros por los bienhechores del colegio. Concluida esta actividad, disfrutaban de un rato de ocio "para platicar con honestidad y modestia". Después debían retirarse al dormitorio hasta las dos de la tarde.

A esa hora, tenían que reunirse en la sala de labor donde escuchaban, hasta las cinco, de voz de la lectora un libro devoto. Descansarían sólo una hora, para que a las seis, otra vez se juntaran en el coro a rezar La Corona de Nuestra Señora, con su letanía, y después tendrían media hora de oración. Acabada la media hora, debían hacer un examen de conciencia, hasta que la rectora dispusiera pasar al refectorio a cenar.

Concluido el tiempo de la cena, debían rezar en el mismo refectorio, tres Padres Nuestros, para luego salir a recrearse hasta el toque de campana. En este momento llegaba la hora de subir a dormir. Las niñas debían dormir en dormitorio común, una en cada cama.

Era obligatorio comulgar los domingos, las festividades de Nuestro Señor Jesucristo y las de María Santísima y festividades de los apóstoles. Si alguna alumna quería hacerlo con más frecuencia, debía tener autorización de su tutor espiritual. No estaba permitido que las alumnas hablaran con nadie, ni recibieran cosa alguna del exterior.

${ }^{1}$ Archivo del Cabildo Eclesiástico de Puebla (ACEP), Puebla, Documentos manuscritos varios, estante 4, casilla 3, 1790 .

${ }^{2}$ Queda entendido, que mientras las niñas cocían, escuchaban la lectura. 
Todas las colegialas debían hacer cada año, los ejercicios de San Ignacio, entrando en ellos el domingo por la noche, hasta el domingo siguiente por la mañana. En tiempos de adviento y cuaresma quedaban prohibidas las visitas.

Por medio de los 21 puntos que conforman el Reglamento del colegio, podemos conocer cómo se distribuía el tiempo de las niñas en un colegio colonial. Su aprendizaje sólo se basaba en recitar bien la doctrina y ejercitarse en la religión; así como en las habilidades de costura o bordado. De esta forma, en horas de rezos y costuras transcurría el tiempo en que desde pequeñas, las niñas se formaban en la obediencia y otras virtudes cristianas. Durante la mayor parte del régimen colonial, la educación de las niñas no pasaba de estos rudimentos. Todavía no se veía la necesidad de que las mujeres aprendieran a leer y escribir. En este sentido, sólo algunas niñas, las que tenían mejores posibilidades de educación, llegaban a aprenderlas.

\section{La educación claustral}

La idea de ampliar la educación a las mujeres se generó en momentos difíciles para la Corona y sus colonias. El siglo XVIII había traído crecimiento y expansión a la Nueva España, pero la reforma económica administrativa de los Borbones, si bien, aumentó los recursos para la monarquía, desorientó su crecimiento. Pronto los nuevos ingresos se distrajeron en las guerras europeas y las buenas intenciones respecto a mejorar la preparación de las mujeres, tuvo un tránsito difícil, que todavía en la segunda mitad del siglo XIX, el Ayuntamiento de Puebla se quejaba de la escasez de escuelas para niñas. ${ }^{3}$

La primera disposición para cambiar la educación de las niñas, vino de España. Fue el rey Carlos III quien ordenó la apertura de escuelas para las niñas, pero en vista de la falta de dinero para establecerlas, acudió a la Iglesia, dispuso que fueran los monasterios y conventos de religiosas los que se ocuparan de esa tarea. Para ello acudió al Papa, por medio de su ministro plenipotenciario en Roma, a fin de buscar la correspondiente autorización para que en los monasterios y conventos de religiosas de Indias fueran admitidas "[...] a la educación las niñas que deseaban colocar muchos sujetos principales". El papa Pío VI, en una breve comunicación del 21 de julio de 1795, aceptó la petición. ${ }^{4}$

Al parecer, en Puebla la disposición fue atendida apenas en 1818 por el obispo Antonio Joaquín Pérez Martínez, quien gobernó la mitra de 1815 a 1821. El prelado envió a todas las religiosas de los conventos, el Reglamento de las nuevas escuelas y una carta en la que manifestaba los beneficios que para las niñas traería la educación. La nueva enseñanza la

\footnotetext{
${ }^{3}$ Archivo del Ayuntamiento de Puebla (AAP), vol. 69 de Expedientes de escuelas, f. 7v, 1830.

${ }^{4}$ Archivo General de la Nación (AGN), ciudad de México, Bienes Nacionales, exp. 50, leg. 607, 1796.
} 
centraba el obispo en tres aspectos fundamentales: la instrucción en la Doctrina Cristiana, la lecto-escritura y la costura; conocimientos, decía su autor, que no sólo realzan los atractivos sino que constituyen diversos grados de utilidad en la vida civil de las mujeres. ${ }^{5}$

Las escuelas, decía el obispo, "[...] no se instituyen para enseñar primores ni curiosidades sino para dar el temprano cultivo que la edad infantil es capaz, y sin el cual es difícil salvarse y absolutamente imposible servir de provecho a la sociedad". 6

Las escuelas llevarían el título de reales y pontificias, serían caritativas, gratuitas y temporales. Esto último porque sólo permanecerían abiertas, mientras hubiera necesidad de ellas. El título $2^{\circ}$. del artículo $1^{\circ}$. del mismo Reglamento decía que todas las religiosas quedaban obligadas a la enseñanza. Cada convento debía escoger de entre sus integrantes a seis religiosas para que se dediquen al magisterio de las niñas, las cuales cambiarían cada año y medio. Esas religiosas debían conformar dos turnos, de tres cada uno, para atender los tres ramos de la enseñanza, con igual grado de importancia en cada uno. En los días de clases, quedaban dispensadas de rezar el oficio divino.

El título tercero del Reglamento se ocupa de las discípulas, y dispone que en cada convento sólo se admitieran 25 alumnas. La edad de las niñas sería de entre 5 y 14 años, sin poner como condición su calidad o estado. Sólo quedaba, absolutamente prohibida, la entrada a la niña que tuviera parentesco con alguna religiosa del convento o fuera portadora de alguna enfermedad. Cada niña debía ingresar a la escuela con los útiles necesarios y sólo en caso de extrema pobreza se les proveería de ellos. Debía cuidarse, además, que las niñas llegaran a la escuela "lavadas, peinadas y vestidas".

La Doctrina Cristiana se enseñaría por medio del Catecismo del Padre Ripalda y cuando hubieran avanzado lo suficiente, se incluiría el Catecismo de Fleuri. No se mencionan los textos para la enseñanza de la lectura y escritura. En cuanto a la costura, se dice que se enseñen sólo aquellas labores útiles a las familias.

El tiempo de enseñanza quedaba distribuido en tres horas por la mañana y dos por la tarde, de 9 a 11 y de 3 a 5. Las clases de la tarde debían suspenderse en los meses de lluvia (julio, agosto y septiembre). Otros días de suspensión o asueto eran los días de celebración del convento, la Semana Santa, el día de la Purísima Concepción y Navidad. El tiempo de estudio quedaba distribuido así: De las 8 a las 9 se darían lecciones de leer; de las 9 a las 10 habría clases de coser o escribir; de las 10 a las 11, de Doctrina Cristiana. De las 3 a las 4:30 p. m., leer, escribir y coser, respectivamente; de las $4: 30$ a las 5, el rosario de cinco misterios

\footnotetext{
${ }^{5}$ ACN, Ramo Bandos, exp. 115, 1818, pp. 296-303. Archivo Histórico de la Biblioteca Lafragua, Puebla (AHBLP), Reglamento para las escuelas gratuitas de niñas educandas establecidas en los conventos de religiosas de Puebla de los Ángeles, dispuesto por el llustrísimo Señor Dr. Don Antonio Joaquín Pérez Martínez. Obispo de la misma diócesis del Consejo de S.M., Puebla a MDCCCXVIII, Oficina de Pedro de la Rosa.

${ }^{6} / \mathrm{dem}$.
} 
con un ligerísimo ofrecimiento en que se pida por las necesidades de la Iglesia y del Estado. Los sábados en la tarde se añadirán los de fe, de esperanza y caridad, por algún breve formulario de los que hay aprobados e impresos.?

Las horas de estudio iban combinadas con los ejercicios religiosos y el aprendizaje de las reglas de buen comportamiento o "máximas de urbanidad y respeto". Anunciaba el obispo Pérez Martínez en el Reglamento que según fueran consolidándose los estudios, en las escuelas se presentarían exámenes solemnes, para que el público fuera testigo del aprovechamiento de las niñas y el servicio que las religiosas prestaban a la Patria.

Si bien, con la aparición de estas escuelas conventuales, gratuitas, se pretendía ampliar la educación de las niñas a la lectura, escritura y cuentas. Además de extenderla a las niñas de bajos recursos, vemos que el sistema de enseñanza no funcionó como debía; la distribución del tiempo todavía nos recuerda al de las escuelas coloniales. Por otro lado, no todas las instituciones fortalecieron el proyecto educativo. Fueron pocos los conventos de monjas que atendieron la orden real de participar en la educación de las niñas. Pese a los llamados del obispo, se resistieron a participar. En la memoria presentada al Congreso en 1829, se informa que en Puebla, sólo cuatro conventos tenían escuelas. El Convento de Jesús María que atendía a 19 niñas, 11 de gracia y ocho de paga. El de San José de Gracia, con 30 niñas, 22 de gracia y ocho de paga. El de Guadalupe, con 23 alumnas, 17 de gracia y cinco de paga. Finalmente, el de Nuestra Señora de los Gozos, con 23 educandas, 10 de gracia y 13 de paga (Staples, 2005: 385). En total, según estos datos, las escuelas conventuales atendían sólo a 122 alumnas, cifra muy reducida y distante de las necesidades de una población de 60,157 habitantes (Tanck, 2010: 91).

Es interesante reiterar que el principal objetivo de las nuevas escuelas, siguió siendo la instrucción en la Doctrina Cristiana. Al respecto Anne Staples señala que de esta doctrina dependía, "[...] el ejercicio reflexivo de la religión y buenas costumbres". Se consideraba también que la enseñanza era encaminada a lograr que las mujeres aprendieran a comportarse adecuadamente, respetar y obedecer a sus superiores. Se trataba como lo refiere Staples de "Una educación más sentimental que intelectual” (Staples, 2005: 389). De la lectura, escritura y cuentas, nos queda la duda: ¿Cuántas monjas en los conventos, sabrían leer y escribir, y cuántas estarían capacitadas para trasmitir esos conocimientos a las niñas?

\section{La Junta de Caridad}

El interés del Rey en la difusión de la educación, también, fue acogido por otros miembros de la Iglesia, quienes con otro tipo de fondos buscaron atender el llamado real. Fue el presbítero 
Antonio Ximénez de las Cuevas quien en 1802, ante la falta de recursos, propuso un medio más práctico y eficaz para atender el problema: la creación de una Junta de Caridad, considerando el abandono en que se hallaba la educación popular y "[...] la pronta aparición de pseudo filósofos que no cesan de inspirar por todos los medios la corrupción de la juventud".

La idea del presbítero no logró su pronta ejecución. En 1802, encontramos al mismo Ximénez de las Cuevas solicitando autorización para colectar limosna y poder erigir la Junta para una mejor educación de la niñez y dos escuelas de sordomudos. La respuesta a esta petición llegó en 1804, cuando le negaron acudir a la caridad para realizar la obra; so pretexto de que el proyecto era amplio y requería mucho dinero, dinero que no había, debido a la pobreza del reino y a las guerras de España. Sin embargo, con la negativa vino la solución: le sugirieron acudir directamente a personas acomodadas del reino y fuera de él, personas que voluntariamente quisieran contribuir. ${ }^{9}$ Así, la Junta de Caridad y Buena Educación fue aprobada por Real Cédula de Fernando VII, el 28 de abril de 1812, con 25 socios europeos y americanos, 13 eclesiásticos, 12 seculares, más otros 12 socios corresponsales.

En 1824, la Junta de Caridad y Sociedad Patriótica para la Buena Educación estableció una escuela de niñas en la Iglesia de Nuestra Señora de los Gozos. El nuevo local quedaba bajo el patrocinio de la Purísima Concepción y del Patriarca José de Calasans, aprobado por el H. Congreso del Estado. El propósito educativo de la novel institución, decía su reglamento, era fomentar "la buena educación de las niñas", basada en los principios de la fe católica, en las buenas costumbres y ejercicio de las virtudes, así como las labores propias de su sexo [sic]. ${ }^{10}$ Las maestras se nombrarían, sólo después de que aprobaran ante la Junta un "riguroso examen" e informe de "[...] religiosidad, modestia, aun en el traje, peinado, desgote, calzado, habilidad en el oficio y afecto al sistema de república federal". El sueldo de las maestras era el estipulado por la Junta, y en vista de que era muy magro, sólo atenderían a 30 niñas pobres, y se les concedía recibir en las escuelas a 10 niñas de paga. Esta situación se consideraba temporal, mientras se pudiera completar el sueldo. Se recomendaba a las maestras tratar por igual a todas las niñas, sin manifestar preferencias.

Todas las niñas, mientras fueran pobres, serían admitidas con regularidad en la escuela. Quedaba prohibido admitir a niños y niñas menores de cuatro años, así como aquellas que portaran alguna enfermedad contagiosa. No se permitiría, ni ahora, ni en el futuro, que la escuela quedara junto a otra que atendiera niños. Requisito indispensable era que las niñas llegaran limpias y aseadas y que se comportaran "con modestia y quietud".

Un día de clase o una semana empezaba y terminaba según las disposiciones del reglamento así:

\footnotetext{
${ }^{8}$ ACEP, Libro de asuntos varios 1, p. 257, 1802.

${ }^{9}$ AHBLP, exp. 1, doc. 2, 1804.

${ }^{10}$ AHBLP, Puebla, Expediente 3, documento 13, 1824.
} 
- Todos los días comenzará la distribución con la señal de la Santa Cruz, un credo en honor de la Santísima Trinidad, y tres Aves Marías a la Purísima Concepción de Nuestra Señora; y terminará con un Padre Nuestro y un Ave María en honor del Santo Ángel de la guarda, y por las tardes igual Padre Nuestro en honor de San José Calasans para comenzar, y otro al finalizar la tarde al patriarca San José y el Acto de Contrición. Los sábados por la tarde se harán los actos de fe, esperanza, caridad y contrición, se rezará el santo rosario al santísimo patriarca José y con el trisagio terminará la semana. ${ }^{11}$

- La enseñanza de la Doctrina Cristiana, propósito central de la escuela, era mediante el Catecismo del padre Ripalda, y para las más adelantadas se usaría el del abad Fleuri y el compendio del Catecismo de las escuelas pías. Para la enseñanza de la costura se recomendaba seguir el método de las escuelas de Madrid: "comienzan por las más fáciles: faja, calceta, punto de red, dechado, dobladillo, costura. Siguiendo, después a coser más fino, bordar, hacer encajes; y a otras, las más adelantadas, pueden hacer cofias, monteras, borlas, bolsillos, sus diferentes puntos, cintas caceras de hilo, cintas de cofia, galón y toda clase de listonería". 12

- La enseñanza de la lectura era por las tardes. En esas horas, se enseñaba a leer y contar, y sólo cuando supieran leer se les enseñaría la escritura. Para la escritura, se recomendaban las muestras escritas y gravadas por Don José Ascencio, esto para que todas las niñas uniformaran la letra, aprendiendo y haciendo una escritura peculiar de la escuela. Se recomendaba que en la lectura, escritura y cuentas, las alumnas sólo aprendieran lo necesario para un gobierno doméstico.

Había días de asueto religioso y civil. Los primeros eran los acostumbrados: Semana Santa, Corpus, los días de San Casiano y San José Calasans, Fieles Difuntos, Navidad y el día del santo de la maestra. Así como los días de exámenes públicos, distribución de premios, llegada de un nuevo papa o su funeral; entrada, consagración o funeral del obispo. Otros asuetos extraordinarios tenían que ver con el nuevo gobierno: celebración de la Independencia y la creación del congreso nacional o del Estado.

Las Juntas de Caridad, asociaciones voluntarias de individuos, buscaron contribuir en el propósito ilustrado de ampliar y extender la educación de las mujeres. Sin embargo, la educación que propagaron siguió siendo rutinaria, religiosa y limitada al número de escuelas que pudieron crear. Plantearon trasmitir una educación con conocimientos útiles para las mujeres, pero siempre dentro del marco de la casa familiar.

\footnotetext{
11 ldem.

12 ldem
} 


\section{Las escuelas municipales}

En 1808, la legislación de Cádiz trajo cambios a la educación de la Nueva España. La Constitución de 1812 ponía en manos de los nuevos Ayuntamientos constitucionales el cuidado de las escuelas de primeras letras. Para el efecto, debían nombrarse dos regidores comisionados para atender todos los asuntos relacionados con las escuelas y amigas. Las cortes, también, promulgaron la libertad de los oficios y la derogación de las ordenanzas gremiales. Así, el gremio de maestros perdió el poder de examinar, visitar y vigilar el ejercicio del magisterio, con lo que estas facultades pasaron al control de los Ayuntamientos. En 1813, se añadió como obligación de los Ayuntamientos el sostener por lo menos una escuela gratuita de primeras letras (Tanck, 1977: 27 y 2010: 89).

En Puebla, estos cambios fueron adoptados con la lentitud que los recursos lo permitían. En 1821, había 22 escuelas de primeras letras, ocho particulares, cuatro gratuitas y 10 escuelas pías de conventos y parroquias. De entre ellas, sólo dos eran para niñas (Tanck, 2010: 91). Por estos datos podemos concluir la poca participación del Ayuntamiento de la ciudad en la educación gratuita. Las escuelas gratuitas de Puebla adolecieron de la misma circunstancia que todas las escuelas del país: la falta de fondos para atenderlas. Los recursos financieros destinados al mantenimiento de escuelas provenían de los derechos pagados por el ingreso de licores extranjeros, del cual se les destinaba el 1\%. Esos fondos se recaudaban en la aduana y de allí pasaban a la tesorería municipal; para su distribución debían esperar la autorización del gobierno estatal.

La mayoría de las escuelas gratuitas a cargo del Ayuntamiento, funcionaban en casas rentadas o salones parroquiales. La falta de recursos por parte de la corporación y la demanda de escuelas para niñas trajeron diferentes formas de actuar de estos establecimientos. Las Ilamadas enseñanzas de niñas o "amigas", eran escuelas que casi siempre nacieron de la iniciativa de los propios profesores. En la casa que ocupaba una escuela de niños, se destinaba un salón separado del resto de la escuela, para enseñanza de niñas, y en donde el profesor proporcionaba el mobiliario y los útiles necesarios. Era la hija, hermana o esposa del profesor quien se hacía cargo del magisterio de la nueva escuela. Con el tiempo, acudían al Ayuntamiento para solicitar "un auxilio" para la escuela, y la corporación, tras el examen correspondiente, daba respuesta favorable, asignando una cantidad de dinero mensual, que podía servir como sueldo de la profesora, renta del local, dinero para tinta y papel, o lo que se conviniera. De esta manera, no existía una cuota uniforme para todas las escuelas de primeras letras; la ayuda venía, según las necesidades más apremiantes de la escuela y la institución corporativa, no siempre, hacia gastos iniciales para establecer una escuela. 
Se llegaba a ser maestro o preceptor de primeras letras, luego de aprobar un examen y ser reconocido por el Ayuntamiento en una escuela que ya existía. Queda claro que muchos de los progresos en la enseñanza de las primeras letras se debieron a la iniciativa de los maestros. Por ejemplo, las escuelas se veían beneficiadas con aumentos de mesadas, aumentos de sueldos y premios para los alumnos, después de que el preceptor mostraba los adelantos de los estudiantes en un examen público.

Otros profesores se esforzaban en elaborar planes para el mejoramiento de la enseñanza, con el único propósito de lograr reconocimiento. En 1818, don Vicente Uranga presentó al Ayuntamiento un cuaderno manuscrito en donde reunió todas las cuentas "útiles, selectas y necesarias" para facilitar la instrucción de la aritmética y ayudar a los padres de familia a ahorrar en la compra de libros.

En 1827, la Comisión de Educación del Ayuntamiento discutió, reformó y adicionó el método de enseñanza Arte para la enseñanza de niños y niñas por el sistema mutuo compuesta por el ciudadano Félix Mandarte. La idea era adecuar esta propuesta para después, ponerla en práctica en las escuelas de la capital del estado y todo el distrito de Puebla. ${ }^{13}$ No encontramos datos sobre el destino de estos proyectos en el sistema de escuelas gratuitas del Ayuntamiento poblano, pero lo que sí es seguro, es que innovaciones como éstas fueron puestas en práctica en las escuelas que dirigían los autores, beneficiando a los estudiantes. Resulta interesante aclarar que la tercera parte del proyecto del profesor Mandarte, contiene el método de enseñanza que deberían llevar las niñas; ahí se establece que debe seguirse el mismo régimen que prescribe el autor para los niños, excepto, el ramo de la costura. Cuando se hizo la revisión de la propuesta, la Comisión de Educación del Ayuntamiento poblano, decidió que por el momento no trataría nada sobre esta parte, dejando ver su desinterés sobre el asunto, o bien, su desconocimiento.

Las escuelas de primeras letras de la ciudad se regían por el Reglamento dispuesto por el Excmo. Ayuntamiento de esta capital que se observa en la escuela gratuita del Barrio de San Antonio, fechado en 2 de febrero de 1827. En este documento, tampoco se hace referencia alguna a las escuelas para niñas. ${ }^{14}$ Lo mismo sucede en los Planes de Enseñanza Pública del estado de Puebla, aprobados, uno en 1828, y otro en 1829.15 En estos documentos aparecen los lineamientos generales para normar la educación pública del estado, pero no hay mención en cuanto a la importancia de extender la educación de las niñas. Sabemos que para las niñas faltaban escuelas gratuitas y aunque se contaba con escuelas para niños, no sabemos si a ellas también acudían niñas.

\footnotetext{
${ }^{13}$ AAP, vol. 68, Expedientes de Escuelas, fs. 177-237, 1827.

${ }^{14}$ AAP, vol. 69, Expedientes de Escuelas, fs. 118-119; vol. 5, Leyes y Decretos, f. 235; 1827.

${ }^{15}$ AAP, vol. 4, Leyes y Decretos, fs. 31 y 231, 1828.
} 
En 1830 se elaboró otro reglamento municipal: Reglamento de escuelas gratuitas a cargo del Excmo. Ayuntamiento de la capital del Estado Libre y Soberano de Puebla, presentado por el síndico primero, aprobado por la misma corporación en cabildo celebrado el 23 de diciembre de 1830.16 En el capítulo uno de este documento se habla de los ramos de enseñanza y autores por los que se ha de enseñar. El segundo se ocupa de la clasificación de los niños, según fueran avanzando en conocimientos. En el tercero se describe la distribución del tiempo y el método de enseñanza. El cuarto da las reglas para aplicar exámenes. El quinto, sexto y séptimo, respectivamente, hablan de premios, castigos y obligaciones de los preceptores. El octavo, noveno y décimo, se refieren, en orden de aparición, a vacaciones y asuetos, penas y recompensas y útiles. Finalmente, se anexan al reglamento, 16 instrucciones para el funcionamiento de la Comisión de Educación, pero ninguna mención particular sobre la educación de las niñas y la necesidad de ampliar el número de escuelas gratuitas para ellas.

La primera preocupación por legislar y atender el ramo en cuestión, la encontramos en 1838. En esa fecha, el profesor José María Bermúdez, preceptor de la escuela de primeras letras del Barrio de San Antonio, se presentó ante el Ayuntamiento a solicitar que se le asignara una "dotación regular" a la directora de la enseñanza gratuita, de niñas pobres, que había establecido en la misma escuela de niños, ante la demanda de las familias del Barrio. El establecimiento estaba bajo el cuidado de su hija, una joven de 20 años, que trabajaba bajo su tutela. Decían que la escuela proporcionaba a las alumnas, libros, papel, plumas, tinta y demás útiles necesarios para la costura. "El mismo profesor, sin descuidar la escuela de niños que dirige, contribuye en la enseñanza de escritura, ortografía y aritmética".

El Ayuntamiento, luego de hacer una revisión del caso, da una respuesta favorable a la solicitud, pero bajo las siguientes condiciones: Se le asignan 30 pesos mensuales a la preceptora, para pago de renta y útiles. Todas las niñas que ingresen a la escuela han de ser menores de 11 años. El local donde está la enseñanza de niñas, estará bien separado de la escuela de niños, para que ni al entrar, ni al salir puedan mezclarse niños y niñas. Aunque la directora de la escuela de niñas ha de estar dirigida por su padre, éste no asistirá personalmente a la "amiga"; ...no administrará por sí las lecciones, sino inspirará y sugerirá a su hija lo que fuere oportuno. Pero para las explicaciones morales del Heni y Pouget y en la aritmética y ortografía, sí se hará excepción de esta regla, permitiéndose la intervención de Bermúdez; y lo mismo para los exámenes privados.

Se dice además, que la escuela queda bajo la autoridad del Ayuntamiento, en la forma y manera de las demás escuelas gratuitas, sometidas a la inspección de su comisionado y dispuesta a las reformas que se estimen convenientes. Mientras no se establezca un reglamento para escuelas gratuitas de niñas, queda sujeta al reglamento vigente.

${ }^{16}$ AAP, vol. 69, Expediente de Escuelas, f. 140, 1830. 
La directora no debía consentir que las niñas lleguen a la escuela o regresen a sus casas solas, sino acompañadas de su madre o alguna mujer que no sea niña. Una vez que el Ayuntamiento obtenga la licencia del Supremo Gobierno para tomar del fondo destinado a las escuelas, el correspondiente al nuevo gasto, la directora empezará a recibir la contribución y el acuerdo entrará en efecto. ${ }^{17}$

En las líneas anteriores, podemos ver lo que el Ayuntamiento vislumbraba para las escuelas de niñas. Primero, la diferencia con las escuelas claustrales no es muy grande, persisten las mismas costumbres de trato hacia las niñas, edad límite en la adolescencia, prioridad a la Doctrina Cristiana como objetivo primario de su educación, separación de sexos en la convivencia escolar. Sólo aparecen aquí las mismas materias de enseñanza que les daban a los niños.

En septiembre de 1823, circuló una orden, para que todos los jueces de paz invitaran a los niños a acudir a las escuelas y así evitar la vagancia. Aplicar esta medida trajo algunos inconvenientes, pues para los hombres había lugar en las escuelas, pero para las mujeres, cuya población era mayor, no existían escuelas. En la ciudad de Puebla, tan sólo existía una escuela dotada por el Ayuntamiento; había otras dos, pero sostenidas por particulares: la de la Junta de Caridad o de los Gozos y la de la Academia. Estas últimas, debido a su precaria situación estaban a punto de cerrar.

En 1830, la Comisión de Educación, informó nuevamente que en la ciudad no había escuelas para niñas. Pidió al Ayuntamiento solicitar al Gobierno del estado, la apertura de tres escuelas nuevas para niñas, y contribuir para el restablecimiento de la Escuela de los Gozos. No sin antes redactar un reglamento para normar su funcionamiento.

En abril de 1840, la corporación municipal, aprobó la creación de dos nuevas escuelas, una en la calle de Tecali y otra en la calle que va por el Puente del Toro; se les asignaron 30 pesos mensuales para renta del local y sueldo de la preceptora. La justificación del gasto era: "la obligación de procurar beneficio público para que las niñas a más de instruirse en labores propias de su sexo lo sean también en la Doctrina Cristiana y dogmas de nuestra Religión". ${ }^{18}$ El proceso para la creación de las nuevas escuelas duró aproximadamente un año, entre octubre y noviembre de 1840 se realizan los exámenes para proveer de maestras a las nuevas escuelas. ${ }^{19}$

\footnotetext{
${ }^{17}$ Ibidem, f. 237, 1838.

${ }^{18}$ Ibidem, f. 255, 1840.

${ }^{19} \mathrm{Ibidem}$, fs. 272-276, 1840.
} 


\section{La Educación Lancasteriana}

A partir de los años veinte del siglo XIX, empezó a extenderse en México el método de enseñanza mutua o lancasteriano. Método que facilitaba la enseñanza primaria en grupos numerosos, pues un maestro solo podía atender a grupos numerosos de 200 a mil niños, ahorrando, también en útiles escolares. Tan efectivo resultó el sistema, que en 1842, el gobierno entregó a la Compañía Lancasteriana la dirección nacional de la instrucción primaria de todo el país (Tanck, 1973: 495)

En el Decreto firmado por Antonio López de Santa Anna el 26 de octubre de 1842, se habla entre otras cosas de la organización de la enseñanza en todo el país, de las obligaciones de la Compañía, los fondos de subsistencia, las obligaciones de los padres de familia y algunos aspectos del magisterio. Resulta sugestivo conocer algunos de los cambios que por primera vez centralizaban la educación primaria en la República. El artículo $6^{\circ}$ establecía que la Compañía debía publicar cartillas para la instrucción y adoptar los libros elementales más necesarios, al parecer, quitando a los padres de familia el gasto que significaban los útiles escolares.

El artículo $7^{\circ}$ daba a los gobernadores de los departamentos la obligación de establecer escuelas de niños y niñas, una por cada mil habitantes. En el artículo $8^{\circ}$ leemos que en las escuelas a cargo de la Compañía se debe enseñar a leer, escribir, las cuatro reglas de la aritmética y la Doctrina Cristiana. La edad de los estudiantes quedó registrada en el artículo $11^{\circ}$ y sería de 7 a $l 1$ años. Quedaba establecida una escuela Normal para la formación de profesores.

Por lo anterior, podemos ver, que en este nuevo sistema, se trataba por igual a los niños de ambos sexos. Habría escuelas para niños y niñas.

El 5 de diciembre de 1843, en Puebla, se aprobó el Reglamento acordado por la junta lancasteriana, subdirectora de la educación primaria en este departamento, aprobado por el supremo gobierno en 14 del corriente. Para el Departamento de Puebla. En este documento se normaban las actividades de la Compañía Lancasteriana de Puebla, la compañía corresponsal, la junta de vigilancia, las escuelas de instrucción primaria, la escuela de adultos, las escuelas establecidas en el hospicio u otros centros de reclusión; las obligaciones de los padres para llevar a sus hijos a las escuelas gratuitas, los preceptores y preceptoras, los fondos y las reformas. ${ }^{20}$

Una de las obligaciones de la Junta de vigilancia sería visitar las escuelas particulares, con el fin de que los maestros cumplieran con lo que estaba propuesto para la instrucción, y no enseñen nada contrario a la religión, a las buenas costumbres, a las instituciones políticas

20 Ibidem, fs. 278-290; Reglamento acordado por la junta lancasteriana, subdirectora de la educación primaria en este departamento, aprobado por el supremo gobierno en 14 del corriente, 1843. 
y leyes vigentes. En el artículo 19, también se establecía que en el Departamento debía haber una escuela para niños y otra para niñas por cada 10 mil habitantes.

El método de estudio se describía en el artículo 24 y decía que en todas las escuelas gratuitas debía seguirse el sistema mutuo simultáneo; y se enseñaría a los niños la lectura y escritura, las cuatro reglas de aritmética y el catecismo religioso y civil que se adoptare; y a las mujeres se enseñará además la costura nueva y de repaso, al gún tejido y labrado. Podemos ver, por lo dispuesto en esas normas que si bien, la educación primaria generalizaba un método de enseñanza, las materias de enseñanza seguían siendo las mismas, la educación de las niñas, seguía normándose en los mismos parámetros: Doctrina Cristiana, lectura, escritura y costura. A las escuelas asistirían diariamente todos los niños y niñas de edades de 7 a 15 años, a excepción de los que auxilien a su padre en los trabajos del campo o en otra ocupación o enfermedad.

Así, la Compañía Lancasteriana fue un "instrumento al servicio del Estado" (Staples, 1999: 112) que ayudó a conservar prácticas tradicionales y reformar la educación en su método y contenido. Cambió el método pero no la forma. Se amplió la educación a sectores de niños pobres urbanos, incluyendo a las mujeres, y en donde la religión y el civismo se entrelazaban en los catecismos para formar una niñez respetuosa y obediente a sus autoridades.

\section{Consideraciones finales}

Los hombres de la llustración consideraron necesario cambiar la educación de las mujeres, al mejorar su grado de conocimientos y extendiéndola a la mayor parte de la población. En la práctica, la educación de las niñas de la ciudad de Puebla no tuvo mayores cambios. Si bien, a finales del siglo XVIII empezaron a crearse espacios nuevos de enseñanza para las niñas. Las nuevas escuelas promovieron, además de la enseñanza de la lectura y escritura, conocimientos útiles como la costura de blancos, pero siempre dentro del marco de las necesidades familiares, y manteniendo métodos, horarios y propósitos similares a los de las escuelas coloniales. Libros, textos escolares y materias de estudio estaban planeados para preservar las reglas que marcaban el lugar que la mujer debía ocupar en la sociedad. Así, mientras las niñas no pasaran de la edad establecida (11, 12 años), su educación transcurría entre rezos, cantos, deletreos y costura, aprendiendo únicamente lo necesario para "gobernar una casa". La consabida educación "moral, civil y científica" pregonada y aplaudida por los llustrados quedaba limitada al marco del hogar.

Las nuevas escuelas estaban dispuestas para enseñar a leer y escribir y contar, materias a las que antes no todas las niñas tenían acceso. Sin embargo, como dice Anne Staples, la diferencia no estaba en la escuela; en ella las niñas aprendían otras habilidades más que los 
hombres; la distinción venía en las oportunidades que después se permitían a los hombres y no a las mujeres: la educación profesional. Los hombres podían pasar de un nivel escolar a otro hasta realizar una carrera, las niñas apenas cumplían 11 o 12 años y ya no podían continuar en las escuelas. Así, 11-12 años de edad eran los suficientes para aprender lo que debían para administrar un hogar.

En Puebla, el proceso de incorporación de las mujeres fue lento, debido a las características de las instituciones que surgieron: escuelas conventuales, escuelas de la Junta de Caridad y las municipales. Gratuitas pero limitadas en número y contenidos de enseñanza.

Por ejemplo, las escuelas gratuitas, administradas por los nuevos Ayuntamientos constitucionales: los hombres encargados de dirigirlas coincidían en la utilidad y necesidad de la educación primaria, "base de la felicidad y progreso de los pueblos" pero la falta de recursos les impedía crear mayor número de escuelas, dotar de maestros y adquirir los útiles necesarios. Esas escuelas municipales para niñas eran gratuitas y ampliaban sus enseñanzas más allá de la lectura y escritura. Sin embargo, dieron preferencia a los niños y no a las niñas. Vemos que todavía en 1840, los jueces de paz se quejaban de la falta de escuelas para niñas, dotadas por el Ayuntamiento. Cuando llegó la educación lancasteriana, cambió el sistema de enseñanza. Los reglamentos nos dicen que había igualdad de oportunidades entre niñas y niños, pero las materias de enseñanza para las niñas seguían siendo las mismas. La falta de información no nos permite determinar si hubo o no beneficios con el nuevo sistema educativo.

En general, la educación de las niñas fue aclamada por los hombres ilustrados como necesaria, y aunque no hubo consenso de cómo educar a las mujeres en la escuela, sí se tenía claro cuáles eran los propósitos de su educación. Había que prepararlas para ser madres de familia, compañeras del marido, administradoras del hogar, y hasta reproductoras de las nuevas ideas republicanas. Hubo que esperar el nuevo siglo para realmente ver cambios en la educación de las mujeres y verlas participar en el desarrollo del país, cuando al fin incursionan en las profesiones como maestras, secretarias, ocupando lugares en otras tantas profesiones antes reservadas en exclusiva, a los varones.

\section{Siglas}

AAP Archivo del Ayuntamiento de Puebla.

ACEP Archivo del Cabildo Eclesiástico de Puebla.

AHBLP Archivo Histórico de la Biblioteca Lafragua de Puebla.

AGN Archivo General de la Nación. 


\section{Bibliografía}

De la Torre Villar, Ernesto (1988), Historia de la educación en Puebla. Época colonial, Puebla, México, BUAP.

Fernández de Echeverría y Veytia Mariano (1963), Historia de la fundación de la ciudad de la Puebla de los Ángeles en la Nueva España, su descripción y presente estado, t. II, Puebla, Ediciones Altiplano.

Gonzalbo Aizpuru, Pilar (1985), La educación de la mujer en la Nueva España, México, SEP-Ediciones El Caballito.

(1987), Las mujeres en la Nueva España. Educación y vida cotidiana, México, El Colegio de México.

Leicht, Hugo (1967), Las calles de Puebla, Puebla, Secretaría de Cultura/Gobierno del Estado de Puebla.

Muriel, Josefina (1994), La sociedad novohispana y sus colegios de niñas, México, UNAM.

Rodríguez Velázquez, Lucero (2014), La irrupción del libro en la educación de niñas y la apertura de las "amigas gratuitas", tesis de maestría, Puebla, ICSYH/BUAP.

Staples, Anne (1985), Educar: panacea del México Independiente, México, SEP-Ediciones El Caballito.

(1999), "La educación como instrumento ideológico del Estado. El conservadurismo educativo en el México decimonónico", en Humberto Morales y William Fowler (coords.), El conservadurismo mexicano en el siglo XIX (1810-1910), México y Escocia, BUAP-University of Saint Andrews, pp. 103-114

(2003), "Una educación para el hogar: México, siglo XIX", en María Adelina Arredondo (coord.), Obedecer, servir y resistir. La educación de las mujeres en la historia de México, México, Universidad Pedagógica Nacional.

(2005), Recuento de una Batalla inconclusa. La educación mexicana de Iturbide a Juárez, México, El Colegio de México.

Tanck Estrada, Dorothy (1977), La educación Ilustrada 1786-1836, México, El Colegio de México.

Rosario Torres Domíncuez. Profesora investigadora del Colegio de Historia, Facultad de Filosofía y Letras de la Universidad Autónoma de Puebla. Doctora en Historia por la UNAM. Líneas de investigación: Colegios y colegiales del antiguo régimen, Historia de la educación en Puebla, periodo colonial y siglo XIX. Publicaciones recientes: Colegios y colegiales palafoxianos de Puebla en el siglo XVIII, México, IISUE/UNAM-BUAP, (2008); María de Lourdes Herrera Feria y Rosario Torres Domínguez, "El proyecto educativo del Segundo Imperio Mexicano: resonancias de un régimen efímero", Nuevo Mundo Mundos Nuevos, Revista electrónica, Francia (2012); "Cuestionamientos a la existencia del Colegio de San Pablo de Puebla, a raíz de la Independencia", en Leticia Pérez Puente y Enrique González (coords.), Permanencia y Cambio II. Universidades Hispánicas 1551-2001, México, CESU/Facultad de Derecho/unam (2006). 